\title{
$O$ agente da passiva em foco
}

\author{
Nelize Pires de Omena \\ Marli Hermenegilda Pereira \\ Universidade Federal do Rio de Janeiro
}

\begin{abstract}
This article analyses the distribution in real time of the several NPs with the function of Passive Agent in analytical passive constructions, with the purpose of investigating the relationship between their use and the semantic and syntactic features of the context. In this way, it is possible to observe the change in their distribution through time and the strategies for focalizing the agent according to the NP used.
\end{abstract}


$\mathrm{N}$ este trabalho, estamos analisando, de uma perspectiva diacrônica, a distribuição de um dos constituintes da oração construções de voz passiva analítica, expressa o agente (ou experimentador) da ação (ou processo) e, em português, tende a ser formalmente suprimido. Realizado, atualmente, com mais freqüência por um sintagma preposicional (S. Prep.) que se constrói com a preposição por, apresenta variações no núcleo, que pode ser ocupado, mais raramente, por outras preposições. Exemplos:

1 - "A informação foi confirmada em Brasília, pela secretária do Conselheiro Paulo Tapajós, chefe do departamento." ("A queda de um fotógrafo". JB. 25/4/92, p.6)

2 - "A casa era cercada de árvores." (Revista Desfile. 1978, p.180)

3 - "Este lugar, em outro tempo foi povoado com o número de 150 pessoas, sua Freguesia e Parocho." (Informação do Capitão Mor Ignácio José Mongiardino ao Governador da Babia, sobre a Capitania do Espírito Santo. 11 de julho de 1790, p.49)

Convém notar que as ocorrências de sintagmas preposicionais com preposições diferentes de por e de, como, $a$, com, em, entre (de agora em diante, denominadas "outras preposições"), em construções de passiva analítica, assemelham-se a constituintes sintáticos com outras funções. Vejamos o exemplo 3:

"Este lugar, em outro tempo foi povoado com o número de 150 pessoas, sua Freguesia e Parocho." (Informação do Capitão Mor Ignácio José Mongiardino ao Governador da Bahia, sobre a Capitania do Espirito Santo. 11 de julho de 1790, p.49) 
Nesse exemplo, o sintagma preposicional "com o número de 150 pessoas" expressa o agente da ação de povoar, parafraseável em: "por 150 pessoas". Assim, semanticamente, este constituinte pode ser interpretado como agente da passiva, numa estrutura de passiva analítica, embora apresente uma preposição diferente, mais comum em adjuntos adverbiais.

Num outro exemplo:

4 - "...queria-ôs ganhar com a doutrina que entre eles era más conheçida." (BARROS, Joan. In: O Diálogo da Viçiosa Vergonha, século XVI, p.434)

O verbo conhecer no particípio pode ser interpretado como parte da construção verbal na voz passiva (ser conhecido) ou como adjetivo numa função predicativa, exemplo da mudança em que particípios integrantes de locuções verbais são reinterpretados como adjetivos. De qualquer modo, entre eles é um constituinte que expressa o experenciador de conhecer, podendo ser substituído pelo agente da passiva: por eles.

Maximino Maciel (1931, p. 403 a 407) falando sobre voz passiva já dizia: "Na voz passiva o adjunto efficiente, sujeito da voz ativa, geralmente é governado pelas preposições por, per ou de, mas casos há em que às preposições $a$, em e com não se pode recusar a função efficiente, tais como: "A fábrica era movida a vapor"; "O carro é puxado a quatro cavallos"; "Pede-lhe mais que aquele porto seja sempre com a sua frota visitado".

Temos, então, um constituinte que apresenta variantes.

Ora, o agente da passiva integra uma construção de voz passiva que constitui uma perspectiva diferente de apresentação de um evento transitivo. O agente, numa construção de voz ativa, ocupa o ponto mais alto da hierarquia tópica e exerce, geralmente, o papel de sujeito gramatical. Nas construções de voz passiva, no entanto, o agente é demovido da posição de tópico e deixa de ocupar o papel de sujeito gramatical, posição e papel que são ocupados por outro elemento não-agente (Givón, 1990). 
As orações de voz passiva constituem, portanto, uma estratégia de desfocalização do agente. Quando essa desfocalização chega ao ponto de supressão da identidade ou da presença do constituinte agente da passiva, temos o mais alto grau de demoção do agente. Como já dissemos, observa-se, em português, uma forte tendência à supressão ou indeteminação do agente da passiva. Segundo Castelar (1990: 64) já no latim clássico “...o agente da passiva era geralmente omitido na língua oral, reservando-se o seu emprego mais freqüentemente à língua literária."

Pensamos, então, que as ocorrências do constituinte agente da passiva na oração devem funcionar como uma estratégia de focalização do agente em grau inferior ao das construções ativas, mas superior ao das construções passivas de agente suprimido (dedutível) ou indeterminado. E que o uso dos diferentes S. Prep. ${ }^{s}$ na função de agente da passiva não seria aleatório. Características semânticas e sintáticas contextuais favoreceriam o uso ora de um, ora de outro S. Prep.

Propusemo-nos, então a:

- verificar a freqüência do uso dos diferentes S. Prep. ${ }^{\text {s }}$ através do tempo, a fim de observar a progressão da substituição de de por por;

- demonstrar que o tipo de S. Prep. mais produtivo, o prototípico, deve apresentar contextos com características semânticas e sintáticas mais focais, dando maior grau de saliência ao agente.

\section{O TEMPO E A DISTRIBUIÇÃO DOS DIFERENTES S. PREP.S}

$\mathrm{Na}$ pesquisa seguimos os princípios teóricos, métodos e técnicas da Teoria da Variação (Oliveira e Silva \& Sherre, 1996). Trabalhamos com um corpus de língua escrita, constituído de textos escritos a partir do século XIV. ${ }^{1}$ Foram selecionados todos os dados de passiva analítica, em que se tem, entre outros constituintes, a 
presença do paciente na função de sujeito, um verbo auxiliar (ser) seguido do verbo principal no particípio e um agente, representado por S. Prep. (com núcleo preposicional por, de ou outras preposições). Historicamente afirma-se que, no latim, o agente da passiva formalmente representado pelo $S$. Prep $\mathrm{DE}+\mathrm{SN}$ precedeu ao construído com a preposição por. O primeiro aparece, também, em dados do romeno, do italiano, do francês, do espanhol, etc. Enquanto que o segundo parece não ser do latim vulgar, pois é desconhecido do Romeno. Teria surgido mais tarde, na Idade Média, passando para as línguas românicas, substituindo o de na Gália e na Ibéria (ver Maurer Jr., 1959).

Nos primeiros textos do português, porém, o agente da passiva já se construía com as preposições por ou de. O Quadro 1 mostra a distribuição cronológica dos S. Prep. ${ }^{\mathrm{s}}$ agentes da passiva encontrados no corpus. Devido à distribuição irregular dos dados, num ou noutro século, foram amalgamados os dados dos séculos XIV e XV, XVIII e XIX.

\section{Quadro 1 - Dados distribuídos cronologicamente por século}

\begin{tabular}{|l|c|c|c|}
\hline \multicolumn{1}{|c|}{ Tempo } & Outras Prep. & $\begin{array}{c}\text { Preposição } \\
\text { por }\end{array}$ & $\begin{array}{c}\text { Preposição } \\
\text { de }\end{array}$ \\
\hline Séc. XIV e XV & $1 / 28=4 \%$ & $16 / 28=57 \%$ & $11 / 28=39 \%$ \\
\hline Séc. XVI & $8 / 23=35 \%$ & $5 / 23=22 \%$ & $10 / 23=43 \%$ \\
\hline Séc. XVII & $1 / 15=7 \%$ & $8 / 15=53 \%$ & $6 / 15=40 \%$ \\
\hline Séc. XVIII e XIX & $1 / 37=3 \%$ & $34 / 37=92 \%$ & $2 / 37=5 \%$ \\
\hline Séc. XX & $1 / 139=1 \%$ & $125 / 139=90 \%$ & $13 / 139=9 \%$ \\
\hline
\end{tabular}

Constatamos (ver Quadro1) que o número de agentes da passiva expressos aumenta significativamente no século XX. Isso parece dever-se ao incremento do uso da passiva perifrástica nos últimos tempos. Em outra pesquisa que estamos realizando - "As 
formas de indeterminação do agente" - as ocorrências da passiva perifrástica para indeterminar o agente vão aumentando também de freqüência a partir do século XX.

Considerando o uso dos diferentes sintagmas preposicionais agentes da passiva, através do tempo, vemos que das 242 ocorrências registradas, a forma $\mathrm{POR}+\mathrm{SN}$ predomina (80\%). O Quadro 1 mostra que, excetuando-se os textos do século XVI, sua freqüência mantevese ou foi aumentando, enquanto a sua principal concorrente $\mathrm{De}+\mathrm{SN}$ - passou por um processo inverso: mais freqüente nos primeiros séculos, DE+SN representa 15\% do total dos agentes da passiva. As formas constituídas com OUTRAS PREPOSIÇÕES+SN representam 5\% dos dados. Elas são esporádicas (12), registram-se mais casos em textos do século XVI. No século XV não foi registrado nenhum dado.

O gráfico a seguir nos dá uma melhor visualização da distribuição das formas através dos séculos.

\section{Gráfico 1 - Distribuição das variantes por século}

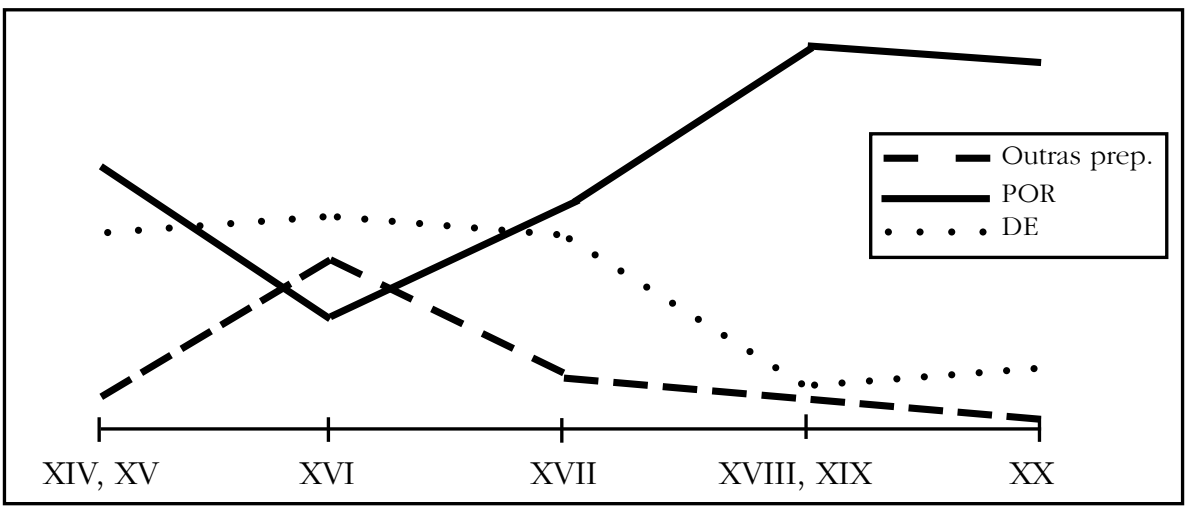

A análise das freqüências registradas no Quadro 1 revela que:

a - Desde o século XIV (não examinamos os períodos imediatamente anteriores: séculos XII e XIII), os diferentes S. Prep. ${ }^{\mathrm{s}}$ agente da passiva estão em concorrência; 
b - Sabendo que o uso da preposição por com esse constituinte é mais tardia que o uso de de, podemos afirmar ser o S. Prep. $\mathrm{POR}+\mathrm{SN}$ a forma inovadora a disputar, digamos assim, o lugar de DE+SN;

c - A princípio, a predominância do uso se alterna, mas a partir do século XVII POR+SN vai substituindo DE+SN, até quase alijá-lo, presentemente;

d - A variante $\mathrm{POR}+\mathrm{SN}$, hoje reconhecida mais rapidamente quando funciona como agente da passiva, é usada com maior freqüência.

\section{A ATUAÇÃO DOS PARÂMETROS FUNCIONAIS}

Considerando que a voz passiva é uma estratégia de focalização do elemento que sofre (ou experiencia) a ação (ou processo) indicado pelo verbo, a forma menos marcada desse uso seria a supressão do constituinte agente da passiva. A forma mais marcada - o agente da passiva expresso - teria a função de salientar em algum grau a agentividade.

Nos dados da amostra ocorreram 1413 passivas analíticas, cujos agentes foram distribuídos assim:

a - Agentes da passiva expressos ...................................... 22\%

b - Agentes da passiva não-expressos, mas dedutíveis do contexto ……................................................... 31\%

c - Agentes da passiva não-expressos nem dedutíveis do contexto (indeterminado) ........................ 47\%

Esses resultados confirmaram ter a passiva analítica, entre outras funções, a de focalizar o elemento que recebe (ou experiencia) a ação (ou o processo) verbal, desfocalizando em diferentes graus o agente. Enquanto a supressão formal do constituinte, sem que haja qualquer pista no texto ou na situação para indicar o agente constitui praticamente a metade das ocorrências, a freqüência dos agentes da passiva expressos é baixa. 
Essa distribuição evidencia uma gradação na desfocalização do agente, com sua presença formal ocupando o nível inferior na escala. Assim, se não é importante para a comunicação, ele pode ficar indeterminado(c) ou disponível(b). Se expresso, a sua presença exerceria alguma função pragmático-discursiva, com características que o tornassem funcionalmente mais saliente.

\section{POSIÇÃO DO AGENTE EM RELAÇÃO AO SUJEITO PACIENTE}

Dentre os três domínios funcionais da voz passiva, apontados por Givón (1991, apud Camacho, s/d), temos "a atribuição de um Tópico para a sentença: o Sujeito/Agente da sentença ativa deixa de ser tópico; em vez dele, atribui-se a função de tópico a um argumento não-agente da sentença ativa". Nossos dados confirmam essa afirmação: 83\% dos agentes da passiva aparecem depois do sujeito/ paciente, os 17\% restantes, porém, ocupam uma posição de tópico, preenchem, portanto, aquela condição de mais saliência que estamos reivindicando para os agentes da passiva expressos.

Resta-nos observar a distribuição dos diferentes S. Prep. ${ }^{s}$ nas posições que antecedem ou sucedem o sujeito/paciente, para verificar qual tipo ocupa a posição mais tópica. ${ }^{2}$

\section{ANTES}

5 - Ex.: “... e pela testemunha foi dito que confirmava o seu depoimento ao qual acrescentava mais algumas declarações.” (Autos do Crime. Uberaba, 1863, p.32)

\section{DEPOIS}

6 - Ex.: "... e que seu filho José na sua moléstia foi tratado por Lúcio Moreira da Silva." (Autos do Crime. Uberaba, 1863, p.7)

Observando a posição em que o agente da passiva se localiza, verificamos que os precedidos por por ocupam, preferencialmente, a posição anterior ao sujeito e os precedidos por outras preposições 
e de tendem a seguirem-se ao sujeito paciente, como mostra o quadro abaixo:

Quadro 2 - Posição do agente em relação ao sujeito paciente ${ }^{3}$

\begin{tabular}{|l|cc|cc|cc|}
\hline Posição & \multicolumn{2}{|c|}{$\begin{array}{c}\text { Outras Preps. } \\
\%\end{array}$} & \multicolumn{2}{|c|}{$\begin{array}{c}\text { Preposição por } \\
\% \\
\text { prob. }\end{array}$} & \multicolumn{2}{|c|}{$\begin{array}{c}\text { Preposição de } \\
\% \\
\text { prob. }\end{array}$} \\
\hline ANTES & $2 / 17=12$ & .223 & $13 / 17=76$ & .469 & $2 / 17=12$ & .308 \\
\hline DEPOIS & $7 / 86=8$ & .455 & $60 / 86=70$ & .216 & $19 / 86=22$ & .330 \\
\hline
\end{tabular}

É portanto o S. Prep. POR+SN o agente da passiva que preferencialmente precede o sujeito paciente, pondo em foco pela sua posição, como na voz ativa, o agente ou experienciador da ação verbal. Como o S. Prep., OUTRAS PREPOSIÇÕES+SN não é um bom representante da categoria, é mais dificilmente reconhecido como agente da passiva, ele não ocupa posição de destaque, daí termos pesos relativos mais altos para os S. Prep. ${ }^{s}$, OUTRAS PREPOSIÇÕES $+\mathrm{SN}$ que ficam depois do sujeito paciente (.455) e .469 para o S. Prep., POR+SN, localizado antes desse tipo de sujeito. DE+SN atua neutramente (próximo a .3) em relação à posição.

Tendo em vista os diversos tipos de construção de voz passiva, verifica-se uma gradação no processo de detransitivação por que passa a sentença na voz passiva. No caso da passiva analítica, em português, em que existe a possibilidade da expressão formal do agente, como nos casos que tratamos aqui, muitos dos aspectos que integram os parâmetros da transitividade permanecem nessas construções.

A presença da agentividade é uma delas. Essa agentividade supõe ação ou ação que desencadeia um processo. Investigando a correlação entre tipos de verbos e a presença das diferentes preposições nos agentes da passiva, observamos os verbos de: 


\section{AÇÃO - PROCESSO}

7 - Ex.: "Empataram em quarto lugar os atiradores, Major Joaquim Mariano de Oliveira e Napoleão Level, tendo sido aproveitados pelo primeiro sete projetis e pelo segundo cinco." (Correio da Manhã. Rio de Janeiro, 1902).

\section{$\mathrm{AÇ} \tilde{A} O$}

8 - Ex.: "Como já te disse, esses volumes serão assignados por nós dois." (Revista Litteras Quadrimestres. Carta XXIV, séc. XIX, p.65)

\section{PROCESSO}

9 - Ex.: "Dentro deste quadro, é fundamental que a comunicação oral e escrita seja perfeitamente entendida por todos." (Redação Vestibular. 1992)

\section{ESTADO}

10 - Ex.: "A exibição do referido filme poderia ser acompanhada de uma conferência sobre o assumpto." (Jornal América Brasileira. $\mathrm{n}$ - $.8,1922)$

São os verbos de ação e/ou processo, aqui amalgamados, que têm, predominantemente, o agente da passiva do tipo POR+SN (.735) (Ver Quadro 3). Esse sintagma representa melhor a agentividade. Os verbos de estado cujos agentes não são prototípicos são o domínio do S. Prep.: DE+SN (.672). A pesquisa mostrou que o agente da passiva realizado por OUTRAS PREPOSIÇÕES+SN admite, no contexto, uma alternância com a preposição por, mas nunca com a preposição de. Neste particular identifica-se mais com POR+SN. Os resultados estatísticos, em relação ao verbo que o rege, aproximamno mais da construção prototípica: .388 para os verbos de ação. 


\section{Quadro 3 - Tipos de verbos}

\begin{tabular}{|l|cc|cc|cc|}
\hline \multicolumn{1}{|c|}{$\begin{array}{c}\text { Tipos de } \\
\text { verbos }\end{array}$} & \multicolumn{2}{|c|}{$\begin{array}{c}\text { Outras Prep. } \\
\%\end{array}$} & \multicolumn{2}{c|}{$\begin{array}{c}\text { Preposição por } \\
\%\end{array}$} & \multicolumn{2}{c|}{$\begin{array}{c}\text { Preposição de } \\
\% \\
\text { prob. }\end{array}$} \\
\hline Estado & $1 / 19=5$ & .285 & $3 / 19=16$ & .043 & $15 / 19=79$ & .672 \\
\hline Ação & $3 / 44=7$ & .388 & $35 / 44=80$ & .454 & $6 / 44=14$ & .158 \\
\hline Ação/processo & $7 / 175=4$ & .130 & $150 / 175=86$ & .735 & $18 / 175=10$ & .136 \\
\hline
\end{tabular}

Ainda enfocando o traço agentividade, tentamos medir as gradações desse atributo nos diferentes S. Prep. ${ }^{s}$ Caracteriza-o um agente capaz de volição, sendo, portanto, animado ou mais precisamente humano. Secundariamente, teríamos um agente semanticamente inanimado ou um experenciador. Essas diferentes características semânticas podem influenciar o uso de preposições diferentes. Avaliamos a correlação entre os diferentes S. Prep. ${ }^{s}$ e os traços semânticos do seu SN.

\section{ANIMADO}

11 - Ex.: "... e que seu filho José na sua moléstia foi tratado por Lúcio Moreira da Silva." (Autos do Crime. Uberaba, 1863, p. 7.

\section{INANIMADO}

12 - Ex.: "A casa era cercada de árvores." (Revista Desfile. Natal. 1978, p.180)

\section{OUTROS}

13 - Ex.: "... e eu queimado era com as chamas dos acendimentos carnaes..." (Boosco Deleitoso. Século XVI, cap. I, p. 4)

O Quadro 4 mostra os resultados relativos à animacidade ou não do agente. 


\section{Quadro 4 - Semântica do agente da passiva}

\begin{tabular}{|l|cc|cc|cc|}
\hline \multicolumn{1}{|c|}{$\begin{array}{c}\text { Semântica } \\
\text { do agente }\end{array}$} & \multicolumn{2}{|c|}{$\begin{array}{c}\text { Outras Prep. } \\
\%\end{array}$} & \multicolumn{2}{c|}{$\begin{array}{c}\text { Preposição por } \\
\%\end{array}$} & \multicolumn{2}{c|}{$\begin{array}{c}\text { Preposição de } \\
\% \\
\text { prob. }\end{array}$} \\
\hline Animado & $5 / 179=3$ & .198 & $49 / 179=83$ & .559 & $25 / 179=14$ & .14 \\
\hline Inanimado & $1 / 24=4$ & .222 & $15 / 24=63$ & .242 & $8 / 24=33$ & .536 \\
\hline Outros & $6 / 39=15$ & .602 & $24 / 39=62$ & .196 & $9 / 39=23$ & .203 \\
\hline
\end{tabular}

O maior peso relativo para o traço animado (.559) do S. Prep. POR+SN salienta os atributos importantes do agente da passiva: sua animacidade e volição. Para o S. Prep. DE+SN o traço inanimado é o mais predominante (.536), sendo também o menos caracterizador do agente, pois lhe falta o atributo volição. O S. Prep. OUTRAS PREPOSIÇÕES+SN que fica, muitas vezes, numa zona limítrofe entre as funções agente da passiva e adjunto adverbial, o que provoca dúvidas quanto a sua classificação como agente da passiva, integra agentes da passiva semanticamente abstratos (outros): .602.

A impessoalização, outro dos domínios funcionais da passiva propostos por Givón (1991, apud Camacho), quando diz: "suprimese a identidade/presença do Sujeito/Agente da sentença ativa”, pode aparecer quando da ocorrência de SNs indeterminados. A expressão de um agente da passiva com um SN de referência mais determinada, mais específica diminui o grau de sua detransitivação, tornando-o mais saliente. Calculamos então o efeito do tipo de referência do SN na composição do S. Prep.

\section{INDETERMINADA}

14 - Ex.: "Hoje a missa da Aurora está um pouco esquecida, sendo rezada, quase sempre, num altar lateral por um ou dois padres." (Revista Desfile. Natal, 1978, p.42) 


\section{DETERMINADA GERAL}

15 - Ex.: "A intenção da reportagem foi chamar a atenção dos leitores para um problema que está preocupando os cientistas e poderá ser resolvido pelo próprio bomem." (Revista Realidade,1974, p.4)

\section{DETERMINADA ESPECÍFICA}

16 - Ex.: "Como já te disse, esses volumes serão assignados por nós dois." (Litteras Quadrimestres. Carta XXIV, p. 65.)

\section{Quadro 5 - Referência do agente da passiva}

\begin{tabular}{|l|cc|cc|cc|}
\hline \multirow{2}{*}{$\begin{array}{c}\text { Referência } \\
\text { do agente }\end{array}$} & \multicolumn{2}{|c|}{$\begin{array}{c}\text { Outras Prep. } \\
\%\end{array}$} & \multicolumn{2}{c|}{$\begin{array}{c}\text { Preposição por } \\
\%\end{array}$} & \multicolumn{2}{c|}{$\begin{array}{c}\text { Preposição de } \\
\%\end{array}$} \\
& \multicolumn{2}{|c|}{ prob. } & \multicolumn{2}{c|}{$\begin{array}{c}\text { prob. } \\
\text { prob. }\end{array}$} \\
\hline + Det.Específica & $6 / 154=4$ & .281 & $129 / 154=84$ & .518 & $19 / 154=12$ & .12 \\
\hline - Indeterminada & $3 / 65=5$ & .223 & $45 / 65=69$ & .301 & $17 / 65=26$ & .476 \\
\hline + Det. Geral & $3 / 23=13$ & .487 & $14 / 23=61$ & .195 & $6 / 23=26$ & .318 \\
\hline
\end{tabular}

A indeterminação do agente da passiva, como vimos, é realizada, predominantemente, pelo constituinte nulo. Se ele é expresso (Ver Quadro 5), a forma prototípica, com a preposição por, é a de referência determinada e mais específica (.518), transmitindo maior grau de informação em relação à determinada generalizante, realizada por OUTRAS PREPOSIÇÕES+SN (.487). Essa última é menos indeterminadora do que a realizada por $\mathrm{DE}+\mathrm{SN}$ com que predominam os sintagmas indeterminados (.476).

\section{CONCLUSÃO}

A análise diacrônica da distribuição dos diferentes S. Prep. ${ }^{\text {s }}$ mostrou-nos a consolidação de POR+SN como o melhor representante hoje do constituinte agente da passiva nas construções de 
passiva analítica. E como acontece nos casos de mudança, a construção substituída $\mathrm{DE}+\mathrm{SN}$ não desapareceu de todo, mas permaneceu preenchendo espaços funcionais que lhes são próprios. OUTRAS PREP. ${ }^{\mathrm{s}}+\mathrm{SN}$, excetuando-se as ocorrências no Séc. XVI, permanece marginal.

Além disso, confirmamos que a opcionalidade de indeterminar, tornar dedutível ou expressar o agente da passiva apresenta-se ao falante como um contínuo de possibilidades funcionais à expressão do evento, segundo seu ponto de vista. Demonstramos, também, que a possibilidade de escolha entre diferentes S. Prep. ${ }^{\text {s }}$ para a expressão do agente apresenta-se como um contínuo de possibilidades para colocá-lo mais ou menos em foco. As características sintáticosemânticas de agentividade, incluindo seu traço caracterizador de animacidade e posição, apontam POR+SN como mais focal, constituindo-se os outros sintagmas variações desse protótipo, em gradações inferiores de focalização.

Esquematicamente teríamos:

$$
\text { Por+ }
$$

$\mathrm{SN}$ - Animado

Det. Específico

Agente/causativo

de uma ação e/ou processo

+ Identificável

+ Foco
De+

SN - Inanimado

Indeterminado

Experienciador

de um estado

+ - Identificável

+ - Foco
Outras Prep +

SN - Abstrato

Det. geral

Agente

de uma ação

- Identificável

- Foco

\section{NOTAS}

${ }^{1}$ Esse corpus constitui o material organizado para a pesquisa "Formas Sintáticas de Indeterminação do Agente", tema da Tese de Doutorado de uma das autoras, em andamento, no IEL, Campinas. Trata-se de um conjunto grande de textos nãoliterários, como: documentos, cartas, diálogos, relatos de expedições, textos de livros de orientação moral ou religiosa e, mais recentemente, reportagens de jornais, artigos de revistas. 
${ }^{2}$ Utilizamos programas do Pacote Varbrul: Checktok, Readtok, Makecell, Crostab, Mvarb, Tvarb e Ivarb. Para calcular não só a freqüência, como também o peso relativo de cada fator das variáveis independentes sobe o uso dos diferentes $\mathrm{S}$ Preps estudados. No cálculo da influência da posição do agente da passiva não foram considerados, obviamente, os dados em que o sujeito/paciente não se realiza formalmente.

3 Devido ao número reduzido de dados, principalmente dos com OUTRAS PREPOSIÇÕES, nós os computamos conjuntamente, baseando-nos no princípio enunciado por Labov, segundo o qual as forças que atuaram no passado são as mesmas que vemos operando hoje (Labov,1975).

\section{BIBLIOGRAFIA}

BORBA, Francisco da Silva. Dicionário gramatical de verbos. São Paulo: Editora Unesp, 1991.

CARVALHO, C. O Pronome se: uma palavra obliqua e dissimulada. Tese de Doutorado, FL - UFRJ, Rio de Janeiro, 1990.

CAMACHO, R. G. Construções de voz, s/d. (Mimeogr.).

HOPPER, P. J \& THOMPSON, S. A. Transitivy in grammar and discourse. Language, 56, p.51-299, 1980.

LABOV, W. On the use of the present to explain the past. Linguistics at the crossroads. Liviana Editrice Jupiter Press, 1975.

MACIEL, Maximino. Grammática discriptiva. Rio de Janeiro: Livraria Francisco Alves, 1931.

MAURER JR., T. H.. Gramática do latim vulgar. Rio de Janeiro: Livraria Acadêmica, 1954.

NARO, A. J.\& VOTRE, S. Emergência da sintaxe como um efeito discursivo. (Mimeogr.).

OLIVEIRA E SILVA, G.M. \& SCHERRE, M. M. Padrões sociolinguísticos. Rio de Janeiro: Tempo Brasileiro, 1996.

REDONDO, J. A. M. Usos do "se". 3. ed. Sociedad General Española, 1974.

SCHERRE, M. M. P. e NARO, A. J. A Concordância de número no sintagma verbal, 1994. (Mimeogr.).

SIEWIERSKA, Anna. Functional Grammar. New York: Routledge, Chapman and Hall, Inc, 1991. 